\title{
Contemporary art, capitalization and the blockchain: On the autonomy and automation of art's value
} 10.2218/finsoc.v2i2.1724

\section{Laura Lotti}

UNSW Australia, Australia

\begin{abstract}
This article addresses contemporary art as a means to investigate how, and to what extent, financial logic impacts upon the socio-cultural sphere. Its contribution is twofold: on the one hand, the article shows that contemporary art's valuation practices increasingly reflect the logic of capitalization; on the other hand, it assesses the emancipatory potential of blockchain technology for the cultural sphere. In relation to the latter I argue that, in spite of the technological novelty of blockchain-based art projects, these nonetheless fail to challenge a received logic of finance. This exposes the limitations to technological determinism as a means of countering financial power in the socio-cultural sphere, and points to new problems for art's valuation methods in relation to the liquid logic of algorithmic finance.
\end{abstract}

\section{Keywords}

Contemporary art, valuation, capitalization, computation, blockchain

\section{Introduction}

In April 2016, the leak of the 'Panama Papers' - a cache of 11.5 million documents dating from 1977 to 2015 - revealed the secretive dealings of more than two hundred million shell companies set up by corporate service provider Mossack Fonseca (Dunn, 2016; ICIJ, 2016). In addition to the individuals and financial institutions from more than two hundred countries implicated in this global network, art figured prominently as an asset class used to store value and avoid taxes and restitution claims (Sutton and Voon, 2016). The Panama Papers thus provided an unprecedented outlook on the deep connections between art and offshore finance, whose covert operations were instrumental in the institutionalization of the contemporary global art market in the 1990s. ${ }^{1}$ This demonstrates how art is not immune to market dynamics, which are in fact penetrating "ever more deeply into the texture of human life" (Cooper and Konings, 2015: 242), often operating below the threshold of visibility and 
perception. Arguably, the proliferation of computational practices of listing, sorting, matching, and ranking has established new orders of continuity among these fields (Lury et al., 2012), undoing the differences between finance and culture, markets and societies, economics and politics, money and data. This is consistent with the neoliberal project of extending market logic to the psycho-social sphere (Foucault, 2008; Mirowski, 2014) and flattening value systems on the same plane of equivalence - economic value.

In light of such arguments, which stress the centrality of financial dynamics to cultural and social life, this article investigates the extent to which financial logic is deployed in the socio-cultural sphere, foregrounding the peculiar condition of contemporary art in relation to the technological infrastructure of global finance. My goal is neither to propose an economic study of contemporary art, nor to discuss finance from an artistic perspective. Acknowledging the fundamental role that automated computational methods play in both cultural and financial dynamics, I engage instead with the algorithmic infrastructure underlying both global finance and contemporary art's "informational milieu" - the "dynamic process of exchange among artist, artwork, and network" (Moss, 2013: para. 1) that encompasses cultural and technical, but also institutional and financial relations. ${ }^{2}$ In doing so, I aim to uncover the sociotechnical operations that enable a shared understanding of contemporary art's valuation in relation to pricing and which, in many cases, also expose it to critique. This article therefore addresses contemporary art as it constitutes itself through dynamic relations of exchange within its informational milieu (which, I argue, increasingly reflects today's financial logic). Furthermore, I explore the possibilities for contemporary art to emancipate itself from the logic of algorithmic finance through the blockchain - the underlying data structure of the Bitcoin protocol.

Contemporary art is highly relevant to an understanding of the cultural logic of finance. This is because it embodies and makes explicit the tensions between pricing and valuation, especially in light of the intertwining between automation and the creative effort that characterizes artistic production. While the former relies on complex computational models and abstract financial metrics, the latter encompasses the material, semiotic, and relational conditions that constitute art's worth and that struggle to find any correspondence in the market. In this context, contemporary art's insistence on value creation puts it at odds with the logic of financial power, which aims to subject social and cultural dynamics to automated pricing mechanisms. What is at stake in this context is the automation, and autonomy, of art's value through the logic of algorithmic finance.

After introducing the relation between contemporary art, finance, and power, I explore how the socio-cultural logic of finance is becoming increasingly embedded within contemporary art's informational milieu through novel valuation practices. Subsequently, I introduce Bitcoin and present art experiments that attempt to emancipate contemporary art, both legally and economically, through the blockchain. By discussing such projects, my goal is to test the potentialities and limitations of the new technology vis-à-vis the pervasiveness of algorithmic-financial logic in art and culture at large - what Malik and Phillips (2012: 220-21) call the "financiality" of contemporary art. I conclude by reflecting on the new possibilities and challenges for the cultural sector ushered in by blockchain technology.

\section{The power of finance and the financiality of art}

In recent years, political economists have drawn attention to the ways in which contemporary finance impacts the socio-cultural sphere. According to Bryan and Rafferty (2006), the logic of 
derivatives proceeds according to a double movement of temporal binding and blending that erases the differences between money, capital, and commodities. In doing so, it flattens the heterogeneity of things and relations onto the computational plane of the market (see also Bryan and Rafferty, 2010). For these authors, derivatives allow for the commensuration of all forms of capital: "They make it possible to convert things as economically nebulous as ideas and perceptions, weather and war into commodities that can be priced relative to each other and traded for profits" (Bryan and Rafferty, 2006: 12). In doing so, they also constitute a new kind of unregulated money. Going further, Amato and Fantacci (2011: 224) argue that the problem foregrounded by derivatives lies with the paradigm of liquidity as the "architectural principle" of the financial infrastructure of the past three hundred years. To these authors, liquidity is the modus operandi of financial capitalism, which relies on the indefinite deferral of payments by monetizing the value of future assets/investments in the present. This enables the capitalist process of differential accumulation that, according to Nitzan and Bichler (2009: 153), corresponds to the power of capitalization: "the algorithm that generates and organizes price". According to them, capitalization impacts social and collective dynamics through the 'creordering' of the social sphere, by which the convergence of processes of capitalization and technical transformation allows owners of capital "to lever technical change ... as a tool of power[;] ... use the monetary symbols of prices and inflation to restructure power[;] ... and perhaps more importantly, ... permits them to reorganize power directly, by buying and selling vendible ownership claims" (Nitzan and Bichler, 2009: 306, emphasis in original).

These studies thus foreground the contemporary logic of finance as a theory of power, which organizes the socio-cultural sphere through the extension of pricing mechanisms to dynamics previously exempt from it. In order to understand how art fits within this schema, it is necessary to also define art from a financial perspective. On the one hand, art objects are considered 'consumer durables', since they do not provide any monetary benefits; on the other hand, they are regarded as an alternative capital asset class that yields a return for their appreciation over time in secondary markets (McAndrew, 2010: section 4). Due to the paradoxical nature of art as an object of economic exchange, economists have traditionally discouraged investments in art markets as they are poorly regulated and entail high transaction, insurance, and storage costs. Furthermore, art investments have a high liquidity risk due to their subjective valuation and the emotional, fleeting nature and limitedness of both supply and demand (McAndrew, 2010: section 6). Yet in the current climate of economic uncertainty, art has become increasingly commoditized, collateralized, and employed as an alternative asset. In the process, it has become, according to investment banks and consulting agencies, an ideal tool for inflation hedging (see Deloitte and ArtTactics, 2014). This is due to the perception that art markets are only weakly correlated to traditional asset classes and so can diversify risk in investment portfolios. The appeal of art as an asset class is evidenced by recent statistics: in 2015, the global art market achieved total sales of $\$ 63.8$ billion, 46 percent of which derives from contemporary art auctions (Kinsella, 2016).

The illiquidity and high transaction costs of art assets would seem to put contemporary art at odds with a theory of financial power premised upon the fluid transformation of assets into money and the differential accumulation of value. Nevertheless, Malik and Phillips (2012: 212) argue that contemporary art embodies the "truth of finance" precisely for its failure to comply with standard free-market logic. They maintain that contemporary art offers better access to the reality of the speculative logic of global finance because it is stripped of "the legitimizing, retro-fitted measurements and theories seeking to justify earnings on the basis of production (Marxism) or consumption (neoclassical liberalism)" (Malik and Phillips, 2012: 220). Drawing on Nitzan and Bichler, they assert that art unveils the logic of capitalization as 
instantiation of power "without any recourse to socio-political accountability" (Malik and Phillips, 2012: 224). Capitalization is traditionally calculated by discounting a company's prospective earnings (e.g., from assets and investments) in order to reflect its supposed present value. However, according to Nitzan and Bichler (2009: 189), capitalization is better grasped through a relation between a hype index, which corresponds to investors' irrational valuation process, and a risk coefficient, that defines the degree of confidence of investors in their own predictions. Building upon this thesis, Malik and Phillips (2012: 223) observe that, by misplacing hype with 'the love of art', which affects the degree of confidence in relation to shifts in liquidity, contemporary art obfuscates the operations of "social ordering for the sake of privatized earnings and is therefore directly power". In other words, contemporary art is a pure expression of the logic of capitalization - of what 'counts' as power; or, of how power counts today. Because of the centrality of the logic of capitalization to contemporary art, the latter cannot be conceptualized in separation from markets and institutions.

While this argument resonates with the current cultural climate - as evidenced by recent critiques of art fairs and biennales ${ }^{3}-$ my goal in this article is to complicate the relation between art and finance by shifting the focus onto their technical entwinement. My proposition is that the 'liquid' logic of capitalization is increasingly reflected in contemporary art's valuation practices. This is evident not only in institutionalized art markets, but also in the 'post-Internet' condition of contemporary art, for which new market formations are emerging (see Vierkant, 2010). ${ }^{4}$ My argument is not that this is due to contemporary art's stylistic choices or metaphorical appropriations; rather, it is because valuation methods in contemporary art increasingly mirror liquidity as the architectural principle of contemporary finance and foundation of capitalization. This, in turn, is directly related to the computational infrastructure that underlies both financial markets and contemporary art's informational milieu. In the next section, I discuss the relation between contemporary art and its underlying algorithmic infrastructure.

\section{Automation and the value of art after the Internet}

Since the 1970s, computational technology has played a crucial role in the constitution and expansion of global financial markets at the same time as it has become central to the organization and standardization of networked socio-cultural dynamics. From this standpoint, approaching the condition of contemporary art vis-à-vis financial logic is by necessity a sociotechnical affair, which requires an acknowledgement of the changes introduced by software into everyday life. As mentioned above, the proliferation of computational practices has established new equivalences between the economic, political, and cultural spheres (see Lury et. al, 2012). Here, I suggest that the shifts registered in the conceptualization of art's value, and in its corresponding valuation practices, are related to the operations of sorting, tagging, and ranking performed by algorithmic technology. These operations do not merely correspond to a technical ordering of data but, more pervasively, are also a cultural ordering that reflects the dynamics of financial power.

The way in which the liquid logic of derivatives impacts the cultural realm is particularly evident in the post-Internet condition of contemporary art, affecting notions of objecthood, authorship, and the cycle of production, distribution, and consumption in art. This has also impacted conceptualizations of art's value, as well the valuation methods associated with it. Reflecting on ambiguities in contemporary art's value in view of changing socio-technical paradigms, Ivanova (2015: 93) argues that the process of abstraction initiated by conceptual 
art has detached contemporary art from its infrastructural and economic reality, thereby neutralizing art's critical thrust and subsuming it within the logic of the market. The result is that, at least since the mid-1990s, contemporary art has become an exercise in self-branding - that is, of strategies to increase artists' viewership and hype; a process that has been further exacerbated by the advent of the 'Web 2.0'. Thus, contemporary art cannot break free from financial power since it is "ultimately geared towards capitalization as a means to market success rather than as a strategy for socially transformative intervention" (Ivanova, 2015: 104). In the present context, this is exemplified by the Facebook newsfeed (see Troemel, 2013; Troemel et al., 2012).

With respect to art's valuation methods, there is a parallel between the increasing automation of the financial sector - aimed at the maximization of differential accumulation through the elimination of the human element ${ }^{5}$ - and contemporary tendencies in the sociocultural realm. This is made evident by platforms such as ArtRank and Artsy. ArtRank is an art market analysis platform that uses data mining and machine-learning algorithms to inform subscribing collectors and institutions, upon payment, about the latest collecting opportunities. In doing so, it reportedly facilitated a 4,200 percent return on investments over a 16-months period (ArtRank, n.d.: para. 2). In contrast to the social interaction required by post-Internet art in the attention economy (see Moss, 2013; Troemel, 2013), ArtRank shortcircuits the valuation process by ranking artists directly on the basis of their sellability. It does this through complex correlations among datasets that involve Google Trends and Instagram data, in addition to "Internet presence, auction results, market saturation, market support and CV data - education, representation, et cetera" (Goldstein, 2015: para. 58). In other words, ArtRank treats artists' names as commodities, and sorts them according to hype on the basis of the circulatory logic of the market. As Bloomberg puts it: "ArtRank gives art the stock market treatment" (Altman, 2015). In this way, ArtRank exacerbates the condition of "Artists Without Art' identified by Brad Troemel et al. (2012: para. 4). This is the condition by which artists are clustered into homogenous groups according to the activity of sorting, ranking, and matching algorithms, ultimately turning contemporary art into self-referential closed loops, so that "the artist-viewer and other artist-viewers are caught in a sphere of perpetual reception and distribution" (Troemel et al., 2012: para. 6).

At the same time, the condition of Artists Without Art is matched by 'Art Without Artists', which indicates the subsumption of art into 'the Curatorial' (Vidokle, 2010). This refers not only to the making of exhibitions, but also to the increasingly determining role of curators as intermediaries between artists and institutions, foregrounding the tendency to "automate the process of art production to render artists redundant" (Vidokle, 2010: para. 14). The condition of Art Without Artists is epitomized by the pervasive and imperceptible activity of platforms such as Artsy. Part social network, part recommendation engine, part digital auction house, Artsy replaces the Curatorial through the Art Genome Project. This initiative consists in classifying art through a vast system of tags, sustained not so much by machine intelligence but by a much less futuristic "curatorial labor" of a group of "Mechanical Turks" (Farago, 2012: para. 3). At the time of writing, Artsy possesses a database of over 350,000 images by 50,000 artists, classified according to 1,000 'genes' (Artsy, n.d.: para. 1), freely available on the repository GitHub. Artsy supposedly aims at the 'democratization of art' in the digital age, but this is not incompatible with its more concrete goal as a start-up - that of increasing its capitalization.

Due to the black-box nature of the algorithms employed by these platforms, it is very difficult to assess the efficacy of such valuation methods within the cultural sphere. As Morris shows in the case of the music sector, the feedback between users, automated cultural 
intermediaries (which he calls 'infomediaries'), and cultural content can give rise to a "data fundamentalism" based on the belief on the complete objectivity and omnipotence of data (Crawford quoted in Morris, 2015: 459). As ArtRank founder Carlos Rivera puts it: "With the amount of data we have today, absolutely anything can be quantified" (quoted in Goldstein, 2015: para. 25). In addition, 'curation by code' - as Morris describes this practice - has an increasingly important role in challenging received valuation practices in art. Bessy and Chauvin (2013: 97-98) write:

Art dealers not only assess the value of artists by using existing and predetermined valuation frames (made by museums or critics for example), they participate in constructing these frames through their engagement in the birth of artistic movements, aesthetic conventions but also 'price conventions' that circulate on markets.

If the valuation of artworks has historically rested with cultural intermediaries, "curation by code' instead constructs values according to abstract computational practices that operate a necessary reduction of the milieu of reference, exacerbating the opaqueness of such valuation methods.

What is therefore at stake with ArtRank and Artsy is the automation of art's valuation through the commodification and monetization of informational interactive processes (e.g., relations between artists-artworks-networks), and the differential accumulation of the value produced by way of dynamic reordering - a logic that does not differ from that of financial securities.

In the previous section, I explained how derivatives markets proceed according to the double movement of binding and blending identified by Bryan and Rafferty. Similarly, automated recommendation systems "fuel a recursive loop of future cultural recommendations" (Morris, 2015: 460), thereby binding the future to the present and blending the singularities of artworks and art practices into computational-financial metrics. Furthermore, ArtRank exemplifies how the future value of such recommendations is immediately capitalized in the present according to the tendency observed by Amato and Fantacci. From this perspective, the 'value' of contemporary art becomes subsumed into pricing mechanisms and loses any ontological primacy. Stefan Heidenreich's (2016: para. 15) comment on this dynamic is particularly revealing: "Assessing a 'real' value [of contemporary art] is impossible, because reality is an effect of the transaction".

To sum up, I have illustrated the relationship between contemporary art and financial logic, exposing the ways in which art's informational milieu mirrors the dynamics of financial power. Although the enterprises discussed above are extreme cases, they cannot be overlooked as they are compelling examples of the tendency toward the automation of valuation practices in contemporary art and, more broadly, the cultural sphere in the current socio-technical paradigm. Artists, theorists, and critics have however long questioned art's entanglement with markets and digital networks (see Bazzichelli, 2006; Bazzichelli and Cox, 2013). In this context, the invention of Bitcoin has prompted many artists and cultural practitioners to experiment with cryptocurrency and the blockchain as a way to extricate art from financial power. ${ }^{6}$ In the next section, I assess the extent to which projects operating at the intersection of art, finance, and technology actually break with the financiality of contemporary art. 


\section{The case of blockchain-based art}

An exhaustive discussion of Bitcoin, the first truly peer-to-peer electronic cash system, goes beyond the scope of this paper (for more information, see Antonopoulos, 2014; Roio, 2013). Let it suffice to say that the invention of Bitcoin, at least initially, threatened to disrupt the financial establishment by offering a decentralized, anonymous, global payment system that existed entirely outside of institutional finance. Importantly, Bitcoin introduced a new logic of value creation and transmission encoded in the blockchain - Bitcoin's underlying data structure. The blockchain provides a transparent and decentralized way of verifying and validating transactions without the need of any central authority. Furthermore, the network of 'miners' generates new 'coins' and guarantees the system's security. Bitcoin has unique features: first, it is scarce, like gold, but has no materiality that would endow it with an intrinsic value; second, its value cannot be determined by fiat because of its decentralized nature (Bjerg, 2016). This means that, in contrast to traditional fiat currency - which is often characterized as a store of value (see Amato and Fantacci, 2011: 35-42) ${ }^{7}$ - Bitcoin's value is not 'stored' anywhere, emerging instead from the dynamics of the network, through participation and the recognition of a shared worldview encoded in the blockchain (Roio, 2013).

While the novelty of Bitcoin has been appropriated by financial powers that have turned it into a commodity to be traded for a price (see Commodity Futures Trading Commission, 2015; Rizzo, 2015), 'blockchain technology' has gained increasing attention. Although the blockchain itself lacks the function of value generation (i.e., mining), it still provides a transparent and decentralized way of recording, verifying, and validating transactions. Recent technological developments also allow the blockchain to accommodate multiple applications - especially those applications that, in the spirit of Bitcoin, minimize the need to trust centralized institutions by enforcing agreements through cryptography. One example of this tendency is 'smart contracts', the first step toward truly Distributed Autonomous Organizations (DAOs). These are entities in which humans play a marginal role in the almost entirely automated management of internal capital (Buterin, 2014). Due to its potential, blockchain technology has been widely adopted by financial institutions that seek to integrate it into the current banking system (Leising and Robinson, 2015). However, the technology also promises important applications for the realization of online commons (Bollier, 2015).

The enthusiasm for cryptocurrency as a medium of artistic enquiry speaks to the relation between art and the wider techno-socio-economic system. Below I introduce two projects that pertain to contemporary art: Monegraph and Plantoid. By experimenting with blockchain technology, these projects aim to challenge contemporary art's entanglement with its institutional-financial milieu and exit the logic of financial power. My goal in the following sections is to assess whether these experiments break with the financiality of contemporary art. To be clear, I am not interested in these projects as artworks. Instead, I am interested in the ways in which they propose a new logic for the production and distribution of value, and the valuation practices that they foreground.

\section{Monegraph: If you like it then you should put a blockchain on it}

Monegraph (short for 'monetized graphics') is a blockchain-based platform for digital creators invented by artist Kevin McCoy and technologist Anil Dash at the 2014 edition of Rhizome's Seven on Seven. By adding an 'authorship layer' to the blockchain, Monegraph allows artists to take control of their creations and track their works' movements, while preventing their 
permissionless reproduction. By means of Namecoin - one of the hundreds of 'altcoins' inspired by the original Bitcoin protocol - digital artworks are embedded with a cryptographic authentication signature that validates the provenance of a work while at the same time allowing artists to track their works' movements. Dash (2014: para. 5) observes that "physical artists" have traditionally availed themselves of two instruments to "invent value around their work". These are the provenance of an artwork, and the verification of its originality. In the digital realm, artists cannot use these devices, with important repercussions for the value, format, and visibility of their work. In order to overcome these limitations, Monegraph proceeds according to three steps: first, a digital artwork is created; second, the claim to the authorship (or ownership) of the artwork is publicly tweeted; third, the information about the provenance of the artwork is recorded on the blockchain and given a unique ID number as proof of its originality. Thus, every time a work registered through Monegraph is circulated, artists gain a fee.

By dispensing with any third party such as art dealers and galleries (which are in any case scarce for digital art), the Monegraph model sets in motion the 'uberization' of art "with the goal of turning media into tradable assets that pay creators every time they are bought, sold, or licensed" ("Monegraph", n.d.). Yet, like the ride-sharing company, the illusion of artistic emancipation from institutional control comes with the dangers of forced dependence on the provisions of an algorithmic third party, which still retains strong links with the institutional field. Monegraph is in fact being developed under NEW Inc., the first museum-led incubator powered by The New Museum. As in the 'sharing economy', of which Uber is a well-known example, a hypothetical future can be imagined in which digital art platforms like Monegraph become institutionalized, thereby replacing (or simply reinforcing) their brick-and-mortar counterparts (i.e., museums). This process of institutionalization may in turn accelerate the shift from a public ethos of care that characterized museums' role in the industrial age to a privatized love of art carried forth by private-public institutions, as a manifestation of the power of capitalization (Malik and Phillips, 2012: 234).

By pursuing the dream of authenticity and institutional autonomy, Monegraph points to a future in which art may indeed become a currency, but one that is privatized, hyperfinancialized, and hypercapitalized. Monegraph "uses cryptography to bring meatspace scarcity to online art" (Constine, 2014: para. 1), thereby reproposing the immaterial commodity paradigm characteristic of liquid assets identified by Amato and Fantacci. In doing so, Monegraph exposes the financial logic of reification of value through recursive circulation. A work on Monegraph becomes reified the moment it is registered on the Namecoin blockchain and acquires a unique ID number. Furthermore, the circulation of images online allows the work to accrue reputational capital. Monegraph also underscores the fact that it is in the economic exchange of a digital artwork that the speculative logic of contemporary finance is manifested in its clearest form. While a digital artwork - like any digital asset, such as a synthetic derivative - exists only as bits of code, the 'thingness' of the work derives from the perception of its 'value' conveyed through the socio-technical apparatus the work is embedded in.

\section{Plantoid: From distributed autonomous organizations to distributed autonomous art}

In their work Plantoid, the French collective Okhaos adds an aesthetic layer to the distributed logic of the blockchain, pushing further the quest for art's autonomy from institutional powers. Based on the Ethereum blockchain, a Plantoid exemplifies a system of distributed automated governance, based on smart contracts and endowed with internal capital, which relies on 
humans' aesthetic appreciation to reproduce itself. The leading principle of the Plantoid is to make art autonomous, by directly funding the artwork instead of funding artists. Humans serve as "symbiotic pollinators" (Okhaos, n.d.: para. 3) as they provide the Plantoid with the nectar it needs to reproduce itself - Bitcoin. Each Plantoid carries a QR code that connects it to a Bitcoin wallet. When visitors 'tip' the Plantoid with Bitcoin, the Plantoid comes to life and rewards the human with a dance of colors and sounds coming from its steel petals: a direct transaction between aesthetic pleasure and digital currency. When the Plantoid has reached enough funds to reproduce itself, it hires an artist, or a team of artists, and gives them the task of creating a new Plantoid through smart contracts. The design of the newborn Plantoid the aesthetic parameters as well as the business logic - is determined by an evolutionary algorithm, while the participation in the network is coordinated through the blockchain. Each time a Plantoid reproduces itself, a percentage of its funds is transferred back along the lineage as a means of expressing gratitude to its ancestors and remunerating, through Bitcoin, the human element that has enabled the Plantoid's reproduction. In this way, the Plantoid aims to incentivize "'good' aesthetics/genetics" (Okhaos, n.d.: para. 6). In short, the Plantoid realizes a truly aesthetic economy in which relations emerge through the disintermediated conversion of 'beauty' and love of art into money that binds artists, designers, artwork, and audience into a symbiotic relationship.

A Plantoid can be considered the first instantiation of the dream of Distributed Autonomous Art (DAA), in which the indeterminacy and autonomy of art finds its self-realization through the blockchain. As already noted, Malik and Phillips suggest that contemporary art's ethos cannot be trusted since it is embedded in a system in which the power of capitalization dictates contemporary art's dynamics. The Plantoid circumvents this problem by embracing art's place in the market and employing the blockchain to emancipate art from concentrated and hierarchically organized capitalist markets. Yet the trust-no-one attitude may end up reinforcing certain tendencies in contemporary art's ethos. By insisting on the aesthetic autonomy of the art object-network, not only does the Plantoid decenter the position of the human; it also conceals the activity of artists and technicians in art's informational milieu, treating them as 'Mechanical Turks' at the service of the machine. From these premises, one can imagine a not too distant future in which humans may be equally incentivized to participate in the reproduction of a DAA through rewards in stock options based on its total 'value' - its capitalization.

\section{Reorienting contemporary art: It's not all about the blockchain}

Both Monegraph and Plantoid take advantages of the possibilities offered by blockchain technology to emancipate contemporary art from financial logic according to opposite strategies at the extremes of the art-institutional spectrum. Monegraph affirms art's place within institutional settings by leveraging the digital scarcity afforded by the Bitcoin protocol and adding an ownership layer to the blockchain. Plantoid aims instead to free art from its institutional-financial milieu by mobilizing the automated logic of smart contracts and adding an aesthetic layer to it. However, the ways in which they operationalize valuation through pricing are similar. On the one hand, by creating a system that relies on artificial scarcity and transferability, Monegraph treats art as a commodity - i.e., a store of value. Yet the 'value' of each artwork depends on its circulation, which relates to the pricing mechanisms involved in the process of differential accumulation. On the other hand, Plantoid does not impose any pricing system. Instead, by giving primacy to the phenomenal relation between the work and the audience, and instituting a direct conversion of aesthetic appreciation into money (and 
vice versa, as in the case of the Plantoid's pyramid scheme), Plantoid instantiates a model of derivative creation that obscures the inner workings of the financial/genetic/aesthetic machine. In other words, Plantoid does not go beyond the black-box logic of current financial markets. This is because the operations enabling the transformation of aesthetic reward into financial value, and vice versa, are hidden behind an affective interface that thwarts any attempts to untangle financial 'rationality' from 'hype'.

Thus, in spite of the novelty of the underlying technology, the operational logic of these projects reflects the dynamics of contemporary markets. This is a logic by which the difference between commodity and currency is dissolved into the paradigm of liquidity, which grants the commensurability between price and the quantity of accumulated appreciation (i.e., shares, likes, and coins). The latter, in turn, depends on market sentiment and on the circulatory processes dictated by the invisible hand of the blockchain. Thus, in spite of their noble intentions, these projects do not in fact break with the current financial paradigm. On the contrary, they propose a model of value creation and distribution that mirrors the logic of derivatives outlined at the beginning of this article. This entails a process of temporal binding and blending of different forms of capital (e.g., aesthetic, financial, affective, reputational) into a single measure, thereby contributing to the "commodification of everything and the incorporation of all social processes into the profit-making-nexus" (Bryan and Rafferty, 2010: 108). In doing so, these projects testify to the subjection of art's value to pricing mechanisms and the pervasiveness of the power of algorithmic finance, both in relation to the burgeoning cryptoeconomy and to (more or less institutionalized) contemporary art.

This means that the normative power of the blockchain alone is not enough to emancipate art from contemporary financial logic, indicating the limits of a technologically deterministic approach to countering the ways in which financial logic has become "fully imbricated with cultural and psychological dynamics" (Cooper and Konings, 2015: 242). Without diminishing the important contributions that the above experiments are providing to the debate on cryptofinance, a fundamental question remains about the orientation of art in relation to changing socio-technical paradigms. In other words, does making money reflect the ethos of contemporary art? Or is 'blockchain-based art' merely radicalizing art's ethos of capitalization with its authentication, transparent circulation (i.e., tracking), and automationautonomization of valuation methods?

This is not the place to answer these questions in detail. Yet it is important to note that, in spite of the recent "resolution of the Bitcoin experiment" (Hearn, 2016) and the widespread rhetoric about the 'naturalness' of markets brought forth by the economic orthodoxy and various neoliberal contingents (see Mirowski, 2014: 54-56), the rise of cryptocurrency demonstrates that the socio-technical reality that underlies both art and finance is inherently artificial, and therefore malleable and open to interventions. This means that what is at stake for both art, as a manifestation of the truth of finance, and for finance, through the abstraction of 'value', are not art and finance per se, but their modes of existence. These depend not only on their underlying technical infrastructure, but also on the deeper assumptions about what cultural value is and how it is to be assessed.

From this standpoint, and because of its privileged position within the techno-cultural milieu, art can take a key role in the project of steering socio-technical forces (such as finance, institutions, money) away from financial capital due to its capacity to formally intervene in the changing of perceptions and modes of relation, thereby opening up new horizons for different conceptions of value and valuation practices. In other words, instead of making money in the ethos of contemporary art, art could be making money, by devising new models of value creation and circulation that exit the extractive logic of contemporary finance. Whether this 
has to be done through the blockchain or not remains uncertain. It is important to note that the original blockchain architecture - Bitcoin - provides a function of value generation (i.e., mining) radically different from fiat money, which could be turned toward the goal of challenging artistic entanglement with institutional-financial power. Exploring these possibilities, however, is beyond the scope of this article. ${ }^{8}$

Keeping the discussion about alternative monetary technologies open is particularly important for the cultural sector. As a matter of fact, there are many artistic experiments, such as process-based art and research-creation initiatives, for which the current system does not offer an adequate metric of worth. These are the areas that, in the current climate of 'austerity', have suffered the most from the reduction of government funding in major Western countries. ${ }^{9}$ In order to begin such an endeavor there are two immediate questions that need answering. First, when contemporary art talks about value, what kind of value is it talking about? And second, who is this value for - the humans (whether artists or audience), or the computational agents that today extract financial yield from social and cultural practices below the threshold of perception? Answering these questions will require a new definition not of what art is, but of how art is in the age of planetary computation, and in its co-constitution with markets and techno-social dynamics in particular.

\section{Notes}

1. As the report by the International Consortium of Investigative Journalism (ICIJ) disclosed, Mossack Fonseca was involved in the auction of the Victor and Sally Ganz collection in November 1997 that allegedly started the "art market's wild enthusiasm for modern art" (Bernstein, 2016: para. 27; see also Cascone, 2016).

2. Drawing on Simondon, Terranova (2004: 8) defines an informational milieu as "a milieu composed of dynamic and shifting relations" between the "massless flows" of information. Curator Ceci Moss (2013: para. 1) takes up this concept to grasp the changing conditions for art production introduced by computationally mediated culture, including ontological and epistemological shifts in conceptions of art.

3. Reviewing the 2016 edition of Art Basel, Akkermans (2016: para. 10) observes the ways in which the conservative choices of exhibitors and artworks reflect the current political and economic uncertainty: "it seems that in many situations conversations about and around art have become substitute for a public domain that is forever receding under the pressure of capital". The ninth edition of the Berlin Biennale also received mixed reviews for its entanglement with the "economic and image-saturated straitjackets of contemporary culture” (Farago, 2016: para. 12; see also Batycka, 2016).

4. As Vierkant (2010: 3) sums up: "Post-Internet is defined as a result of the contemporary moment: inherently informed by ubiquitous authorship, the development of attention as currency, the collapse of physical space in networked culture, and the infinite reproducibility and mutability of digital materials". 'Post-Internet' also exposes the double concern for both the materiality of the art object and its fluid circulation. New market structures are emerging for post-Internet art, in which the standard distinction between primary and secondary markets is collapsing. This is exemplified by the figure of the 'art-flipper' who, by tapping into the power of social networks, bypasses the traditional order to art markets and focuses instead on short-terms investments aimed at financial gain (see Velthuis, 2014).

5. 54 percent of jobs in finance are reportedly at high risk of automation, more than any other skilled industry. The diffusion of high-frequency and automated trading strategies and the introduction of robo-advisers on Wall Street provide examples (see Popper, 2016; Son and Collins, 2016). 
6. This is exemplified by Artists Re:Thinking the Blockchain, a publication and discourse program proposed by London-based gallery Furtherfield and Torque Books, which aims to "augmen[t] the arrival of the blockchain into the arts" (Torque and Furtherfield, 2016). At the time of writing, it is in crowdfunding phase. Other examples of how blockchain technology has gained traction among artists include the works of Rob Myer and Simon Denny.

7. As Amato and Fantacci (2011: 183-96) explain, the origin of fiat money can be traced back to the invention of central banking in the UK in the seventeenth century, just before the introduction of the gold standard. According to these authors, capitalism structurally relies on the value storage of fiat money, which inaugurated the paradigm of liquidity at the foundation of contemporary finance.

8. Several culture-oriented blockchain platforms are emerging. For example, the cooperative hedge fund Robin Hood Minor Asset Management "uses art as an essential part of social organization, economy, politics and life". In doing so, it aims "to engage directly with art's power to create unforeseen and unthinkable (economic, political, social, emotional, organizational...) processes" (Piironen and Virtanen, 2015: 99). Another notable project is Paul Seidler and Paul Kolling's Terra0, whose goal is to create a self-sustaining, self-owned forest through smart contracts; at the time of writing it is in early stage of development.

9. For instance, in Australia the number of grants to individual artists has decreased by 70 percent since the 2013-14 financial year (Croggon, 2016). This trend has been maintained in the 2016-17 Federal Budget (Watts, 2016).

\section{References}

Akkermans, A. (2016) Hints of the real world in Art Basel's elitist bubble. Hyperallergic, 22 June. Available at: <http://hyperallergic.com/306912/hints-of-the-real-world-in-art-basels-elitistbubble/>. Accessed 23 June 2016.

Altman, A. (2015) Buy, sell, hang on your wall. Bloomberg [Online], 12 November. Available at: $<$ http://www.bloomberg.com/news/articles/2015-11-12/artrank-gives-art-the-stock-markettreatment/>. Accessed 26 July 2016.

Amato, M. and Fantacci, L. (2011) The End of Finance. Cambridge: Polity. Antonopoulos, A.M. (2014) Mastering Bitcoin. Sebastopol: O'Reilly Media. ArtRank (n.d.) FAQ: ArtRank. Available at: <http://artrank.com/pages/faq/>. Accessed 8 April 2014. Artsy (n.d.) About: Artsy. Available at: <https://www.artsy.net/about/>. Accessed 24 March 2016. Batycka, D. (2016) The 9th Berlin Biennale: A vast obsolescent pageant of irrelevance. Hyperallergic, 24 June. Available at: <http://hyperallergic.com/306932/the-9th-berlin-biennale-a-vastobsolescent-pageant-of-irrelevance/>. Accessed 26 June 2016.

Bazzichelli, T. (2006) Networking Art: The Net as Artwork. Aarhus: Digital Aesthetics Research Center. Bazzichelli, T. and Cox, G. (eds.) (2013) Disrupting Business: Art and Activism in Times of Financial Crisis. Brooklyn, NY: Autonomedia.

Bernstein, J. (2016) The art of secrecy. The International Consortium of Investigative Journalists, 7 April. Available at: <https://panamapapers.icij.org/20160407-art-secrecy-offshore.html/>. Accessed 21 April 2016.

Bessy, C. and Chauvin, P.-M. (2013) The power of market intermediaries: From information to valuation processes. Valuation Studies, 1(1): 83-117.

Bjerg, O. (2016) How is Bitcoin money? Theory, Culture \& Society, 33(1): 53-72.

Bollier, D. (2015) The blockchain: A promising new infrastructure for online commons. David Bollier: News and Perspectives on the Commons, 4 March. Available at: $<$ http://bollier.org/blog/blockchain-promising-new-infrastructure-online-commons/>. Accessed 1 October 2015. 
Bryan, D. and Rafferty, M. (2010) A time and a place for everything: Foundations of commodity money. In: Amato, M., Doria, L. and Fantacci, L. (eds.) Money and Calculation: Economic and Sociological Perspectives. Houndmills: Palgrave Macmillan, 101-21.

Bryan, D. and Rafferty, M. (2006) Capitalism with Derivatives: A Political Economy of Financial Derivatives, Capital and Class. Houndmills: Palgrave Macmillan.

Buterin, V. (2014) DAOs, DACs, DAs and more: An incomplete terminology guide. Ethereum Blog, 6 May. Available at: <https://blog.ethereum.org/2014/05/06/daos-dacs-das-and-more-an-incompleteterminology-guide/>. Accessed 1 February 2016.

Cascone, S. (2016) Panama papers reveal Ganz Collection secret. Artnet News, 8 April. Available at: $<$ https://news.artnet.com/market/picasso-panama-papers-ganz-collection-469646/>. Accessed 11 June 2016.

Commodity Futures Trading Commission (2015) CFTC orders Bitcoin options trading platform operator and its CEO to cease illegally offering Bitcoin options and to cease operating a facility for trading or processing of swaps without registering. CFTC [Online], 17 September. Available at: <http://www.cftc.gov/PressRoom/PressReleases/pr7231-15/>. Accessed 25 September 2015.

Constine, J. (2014) Monegraph uses Bitcoin tech so internet artists can establish 'original' copies of their work. TechCrunch [Online], 9 May. Available at: <http://social.techcrunch.com/2014/05/09/monegraph/>. Accessed 20 December 2015.

Cooper, M. and Konings, M. (2015) Contingency and foundation: Rethinking money, debt, and finance after the crisis. South Atlantic Quarterly, 114(2): 239-50.

Croggon, A. (2016) The 70\% drop in Australia Council grants for individual artists is staggering. The Guardian, 18 May. Available at: <http://www.theguardian.com/culture/2016/may/19/the-70drop-australia-council-grants-artists-funding-cuts/>. Accessed 28 May 2015.

Dash, A. (2014) A bitcoin for digital art. The Message, 9 May. Available at: <https://medium.com/message/a-bitcoin-for-digital-art-8c7db719e495/>. Accessed 26 April 2015.

Deloitte and ArtTactics (2014) Art and Finance Report 2014. Available at: <http://www2.deloitte.com/content/dam/Deloitte/at/Documents/Tax/art-finance-report.pdf/>. Accessed 19 November 2015.

Dunn, C. (2016) Dirty little secrets: Inside the 'Wikileaks' of the ultra-rich and ultra-powerful. Fusion. Available at: <http://interactive.fusion.net/dirty-little-secrets/>. Accessed 14 April 2016.

Farago, J. (2016) Welcome to the LOLhouse: How Berlin's Biennale became a slick, sarcastic joke. The Guardian, 14 June. Available at: <https://www.theguardian.com/artanddesign/2016/jun/13/berlin-biennale-exhibition-reviewnew-york-fashion-collective-dis-art/>. Accessed 26 July 2016.

Farago, J. (2012) Artsy and the myth of the online art market. New Republic, 22 October. Available at: <https://newrepublic.com/article/108893/artsy-and-the-myth-the-online-art-market/>. Accessed 24 March 2016.

Foucault, M. (2008) The Birth of Biopolitics: Lectures at the Collège de France, 1978-1979, trans. G. Burchell. New York, NY: Palgrave.

Goldstein, A. M. (2015) ArtRank founder Carlos Rivera on why he's leading the Flipper Revolution-and why it can't be stopped. Artspace, 11 June. Available at: <http://www.artspace.com/magazine/interviews_features/carlos-rivera-art-rank-interview/>. Accessed 26 July 2016.

Hearn, M. (2016) The resolution of the Bitcoin experiment. Medium, 14 January. Available at: <https://medium.com/@octskyward/the-resolution-of-the-bitcoin-experiment-dabb30201f7\#--262-344.puwe6jpse/>. Accessed 15 January 2016.

Heidenreich, S. (2016) Freeportism as style and ideology: Post-internet and speculative realism, Part I. 
e-flux, March. Available at: <http://www.e-flux.com/journal/freeportism-as-style-and-ideology-parti-post-internet-and-speculative-realism/>. Accessed 3 May 2016.

ICIJ (2016) The Panama Papers. The International Consortium of Investigative Journalists, April. Available at: <https://panamapapers.icij.org/>. Accessed 10 May 2016.

Ivanova, V. (2015) Art's values: A détente, a grand plié. Parse, 2: 91-105.

Kinsella, E. (2016) What does TEFAF 2016 Art Market Report tell us about the global art trade? Artnet News, 9 March. Available at: <https://news.artnet.com/market/tefaf-2016-art-market-report443615/>. Accessed 12 March 2016.

Leising, M. and Robinson, E. (2015) Blythe Masters tells banks the blockchain changes everything. Bloomberg, 1 September. Available at: <http://www.bloomberg.com/news/features/2015-0901/blythe-masters-tells-banks-the-blockchain-changes-everything/>. Accessed 19 September 2015.

Lury, C., Parisi, L. and Terranova, T. (2012) Introduction: The becoming topological of culture. Theory, Culture \& Society, 29(4/5): 3-35.

Malik, S. and Phillips, A. (2012) Tainted love: Art's ethos and capitalization. In: Lind, M. and Velthuis, 0. (eds.) Art and Its Commercial Markets: A Report on Current Changes and with Scenarios for the Future. Berlin: Sternberg Press, 209-40.

McAndrew, C. (2010). An introduction to art and finance. In: McAndrew, C. (ed.) Fine Art and High Finance: Expert Advice on the Economics of Ownership. E-book. New York, NY: Bloomberg Press.

Mirowski, P. (2014) Never Let a Serious Crisis Go to Waste: How Neoliberalism Survived the Financial Meltdown. London: Verso.

Monegraph (n.d.) NEW Inc. Available at: <http://www.newinc.org/monegraph/>. Accessed 1 February 2016.

Morris, J.W. (2015). Curation by code: Infomediaries and the data mining of taste. European Journal of Cultural Studies, 18(4/5): 446-63.

Moss, C. (2013) Expanded internet art and the informational milieu. rhizome.org, 19 December. Available at: <http://rhizome.org/editorial/2013/dec/19/expanded-internet-art-and-informationalmilieu/>. Accessed 20 December 2013.

Nitzan, J. and Bichler, S. (2009) Capital as Power: A Study of Order and Creorder. London: Routledge. Okhaos (n.d.) Plantoid. Available at: <http://okhaos.com/plantoid/>. Accessed 10 December 2015. Piironen, P. and Virtanen, A. (2015) Democratizing the power of finance: A discussion about Robin Hood asset management cooperative with founder Akseli Virtanen. In: Lovink, G., Tkacz, N. and De Vries, P. (eds.) MoneyLab Reader: An Intervention in Digital Economy. Amsterdam: Institute of Networked Cultures.

Popper, N. (2016) The robots are coming for Wall Street. The New York Times, 25 February. Available at: <http://www.nytimes.com/2016/02/28/magazine/the-robots-are-coming-for-wall-street.html/>. Accessed 21 March 2016.

Rizzo, P. (2015) CFTC defines Bitcoin and digital currencies as commodities. CoinDesk, 17 September. Available at: <http://www.coindesk.com/cftc-ruling-defines-bitcoin-and-digital-currencies-ascommodities/>. Accessed 25 September 2015.

Roio, D. (2013) Bitcoin, the end of the taboo on money. Available at: <http://www.dyndy.net/2013/04/bitcoin-ends-the-taboo-on-money/>. Accessed 30 April 2014.

Son, H. and Collins, M. (2016) The rich are already using robo-advisers, and that scares banks. Bloomberg.com [Online], 5 February. Available at: <http://www.bloomberg.com/news/articles/2016-02-05/the-rich-are-already-using-robo-advisersand-that-scares-banks/>. Accessed 6 February 2016.

Sutton, B. and Voon, C. (2016) Panama Papers shed light on the shadowy art market. Hyperallergic, 12 April. Available at: <http://hyperallergic.com/289250/panama-papers-shed-light-on-the-shadowy- 
art-market/>. Accessed 14 April 2016.

Terranova, T. (2004) Network Culture: Politics for the Information Age. Ann Arbor, MI: Pluto Press.

Torque and Furtherfield (2016) Artists Re:Thinking the Blockchain. Available at:

<http://www.crowdfunder.co.uk/artists-rethinking-the-

blockchain?tk=208334da9b174c4145e1fec75e784e1b261ff238/>. Accessed 25 July 2016.

Troemel, B. (2013) Athletic aesthetics. The New Inquiry, 10 May. Available at:

<http://thenewinquiry.com/essays/athletic-aesthetics/>. Accessed 29 March 2016.

Troemel, B., Vierkant, A. and Vickers, B. (2012) Club kids: The social life of artists on Facebook. DIS Magazine. Available at: <http://dismagazine.com/discussion/29786/club-kids-the-social-life-ofartists-on-facebook/>. Accessed 29 January 2014.

Velthuis, O. (2014) ArtRank and the flippers: Apocalypse now? Texte Zur Kunst, 96: 35-49.

Vidokle, A. (2010) Art without artists? e-flux, May. Available at: <http://www.e-flux.com/journal/artwithout-artists/>. Accessed 25 March 2014.

Vierkant, A. (2010) The image-object post-internet. Available at:

<http://jstchillin.org/artie/pdf/The_Image_Object_Post-Internet_a4.pdf/>. Accessed 17 January 2012.

Watts, R. (2016) Arts budget 2016 doesn't hurt (much) but doesn't heal. ArtsHub Australia, 3 May. Available at: <http://www.artshub.com.au/news-article/news/grants-and-funding/richardwatts/arts-budget-2016-doesnt-hurt-much-but-doesnt-heal-251192/>. Accessed 2 June 2016. 